\title{
Structure and Chosen Nanomechanical Properties of Amorphous-Crystalline Laser Weld
}

\author{
W. PilarczyK ${ }^{a, *}$, A. KAnia ${ }^{a}$, R. Babilas ${ }^{a}$ And A. PilarczyK ${ }^{b}$ \\ ${ }^{a}$ Silesian University of Technology, Faculty of Mechanical Engineering, Akademicka 2A, 44-100 Gliwice, Poland \\ ${ }^{b}$ Instytut Spawalnictwa, Bł. Czesława 16-18, 44-100 Gliwice, Poland
}

\begin{abstract}
Zr-based bulk metallic glasses attract the attention because of their good mechanical properties and glassforming ability. A laser welding process has been applied to increase the capability of using amorphous materials in the industry. The plates of $\mathrm{Zr}_{55} \mathrm{Al}_{10} \mathrm{Ni}_{5} \mathrm{Cu}_{30}$ alloy were produced by die pressure casting method and welded by the TruLaser Station 5004. X-ray analysis and microscopic observation provided information about the structure and morphology of the cross-section of weld on the boundary of the heat affected zone and the fusion zone. Nanohardness and reduced Young modulus of the particular heat affected zone, fusion zone, and parent material were examined with Hysitron TI950 Triboindenter and with the Berkovich indenter. The presence of the amorphous and amorphous-crystalline phases was confirmed by related tests. The detailed topographic analysis revealed that the heat affected zone demonstrated a slight roughness characteristic of the crystalline phase and a smooth surface in the fusion zone. The main value of the nanohardness of particular weld zones has the similar order of magnitude. In turn, Er value is restricted in the range of $105.76-108.80 \mathrm{GPa}$. The main goal of this work is to present the structure and chosen nanomechanical properties of the $\mathrm{Zr}_{55} \mathrm{Cu}_{30} \mathrm{Ni}_{5} \mathrm{Al}_{10}$ laser weld.
\end{abstract}

DOI: 10.12693/APhysPolA.133.219

PACS/topics: bulk metallic glasses, nanoindenter, surface topography, nanomechanical properties

\section{Introduction}

In recent years, an intense development of bulk metallic glasses has been observed. Currently, maximum dimensions of manufactured elements reach the diameter of several dozens of millimetres, yet the thickness of homogeneous metallic glass is still too small for industrial scale applications. Sufficient dimensions and high enough thermal stability of samples are required for applying bulk metallic glasses in selected engineering processes. The development of the process of joining bulk metallic glasses is a key task which will allow the use of these materials by the industry [1].

Today, laser welding, as a modern joining process, raises a lot of interest among scientists due to advantages of using a laser beam - particularly its characteristics such as weld penetration depth and high energy density. Laser radiation is characterized by high coherence in time and space, and a narrow wavelength range. The basic characteristics of laser radiation are monochromaticity, minimal beam divergence, parallelism and high radiation energy.

According to literature data, attempts were made to join amorphous materials using a laser beam as early as in 2003. Li et al. [2] successfully combined two plates of a $\mathrm{Zr}_{45} \mathrm{Cu}_{48} \mathrm{Al}_{7}$ alloy using the laser welding method. Kim and the team [3] have used a Nd:YAG pulse laser for welding bulk metallic glasses having the chemical composition of $\mathrm{Cu}_{54} \mathrm{Ni}_{6} \mathrm{Zr}_{22} \mathrm{Ti}_{18}$. Kawahito et al. [4] succeeded in welding $\mathrm{Zr}_{55} \mathrm{Al}_{10} \mathrm{Ni}_{5} \mathrm{Cu}_{30}$ metallic glass with a

*corresponding author; e-mail: wirginia.pilarczyk@polsl.pl narrowly focused fibre laser beam. The process of crystallisation in terms of the process was considered in the conducted research, but no detailed analysis was made on how to preserve the amorphous nature at the fusion zone and at the heat affected zone during laser welding. It can be concluded that it is important to understand the mechanism of producing amorphous welds in the process of laser welding.

The main aim of the presented work was to obtain a $\mathrm{Zr}_{55} \mathrm{Cu}_{30} \mathrm{Ni}_{5} \mathrm{Al}_{10}$ laser weld and present the structure and chosen properties of the parent material as well as heat affected and fusion zones.

\section{Experimental procedure}

The sample material was a $\mathrm{Zr}-\mathrm{Al}-\mathrm{Ni}-\mathrm{Cu}$ zirconium based alloy. The procedure for obtaining bulk metallic glasses in the form of plates involved the production of an initial alloy in the form of an ingot and then casting the molten alloy into a copper mould [5]. The test alloy was prepared on the basis of pure $\mathrm{Zr}, \mathrm{Cu}, \mathrm{Ni}$, and $\mathrm{Al}$ elements with a total weight of $30 \mathrm{~g}$, using an induction generator in a ceramic crucible. The casting process of the liquid alloy into a copper mould involved the melting of the initial alloy in a quartz crucible using an induction generator and then raising the crucible plug and introducing the molten alloy into the copper mould with the protective gas pressure.

The PANalytical XPERT PRO MPD X-ray diffractometer equipped with a copper anode X-ray tube was used to identify the phase composition of the heat affected zone and the melt zone. The operating parameters of the lamp were $40 \mathrm{kV}$ and $30 \mathrm{~mA}$. For the purpose of the phase composition analysis, diffraction patterns were performed in the angular range $2 \Theta$ from $10^{\circ}$ to $120^{\circ}$. 
Cross-sectional area observations of the weld were carried out using the ZEISS high-resolution scanning electron microscope SUPRA 35 with the EDS chemical composition microanalysis system.

Nanomechanical properties tests, i.e. nanohardness and reduced Young modulus, and surface scanning of joints were performed using the Hysitron TI 950 Triboindenter with the Berkovich indenter.

\section{Results and discussion}

X-ray diffraction analysis of $\mathrm{Zr}_{55} \mathrm{Cu}_{30} \mathrm{Ni}_{5} \mathrm{Al}_{10}$ bulk metallic glasses in a as-cast state and after laser beam application show that these materials have an amorphousnanocrystalline structure. The X-ray diffraction pattern of the weld (Fig. 1) revealed wide, fuzzy spectra which are characteristic for amorphous structures. Small diffraction lines from crystalline phases were observed as well.

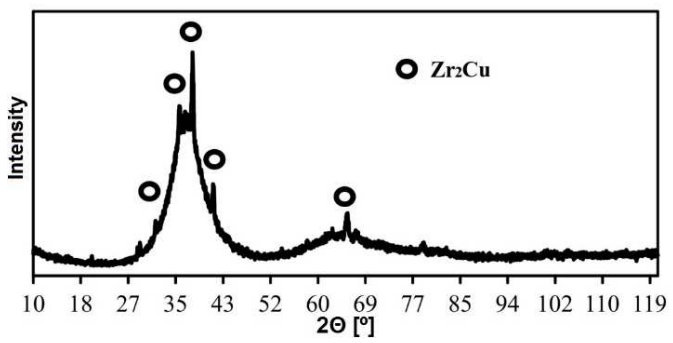

Fig. 1. $\mathrm{Zr}_{55} \mathrm{Cu}_{30} \mathrm{Ni}_{5} \mathrm{Al}_{10}$ alloy X-ray diffraction pattern after casting and after laser welding (weld area, cross-section).

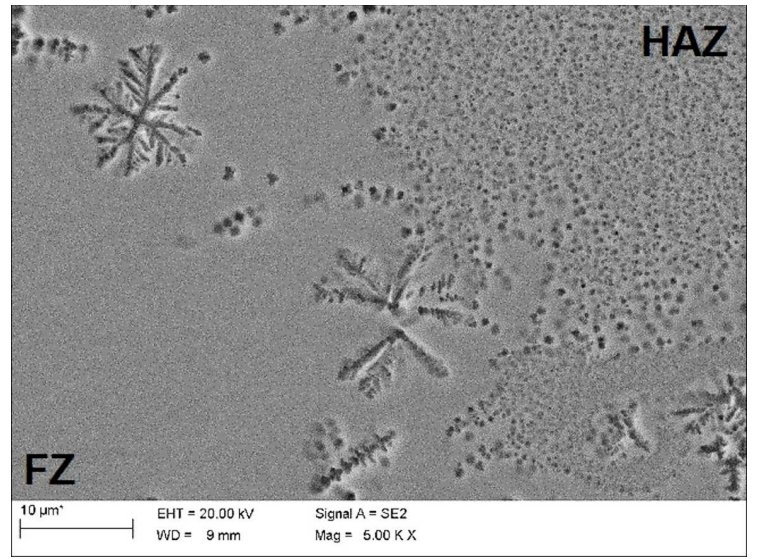

Fig. 2. Morphology of the cross-section of the bulk metallic glass weld based on the Zr matrix; the boundary of the heat affected zone (HAZ) and the fusion zone (FZ).

Diffraction analysis of samples involving the fusion zone and the heat affected zone have shown the presence of lines which originated from the $\mathrm{Zr}_{2} \mathrm{Cu}$ crystalline phase.

Nucleation and growth of crystalline phases is the fastest to occur in the heat affected zone, as indicated by the initial results of X-ray analysis. This may be caused by the chemical affinity for oxygen of alloy elements of zirconium-based alloys (especially $\mathrm{Zr}$ and $\mathrm{Al}$ ) [6, 7] which results in the reduction of the glass-forming ability or a prolonged effect of high temperature on the heat affected zone (HAZ), as well as applying a high pulse energy of the beam laser.
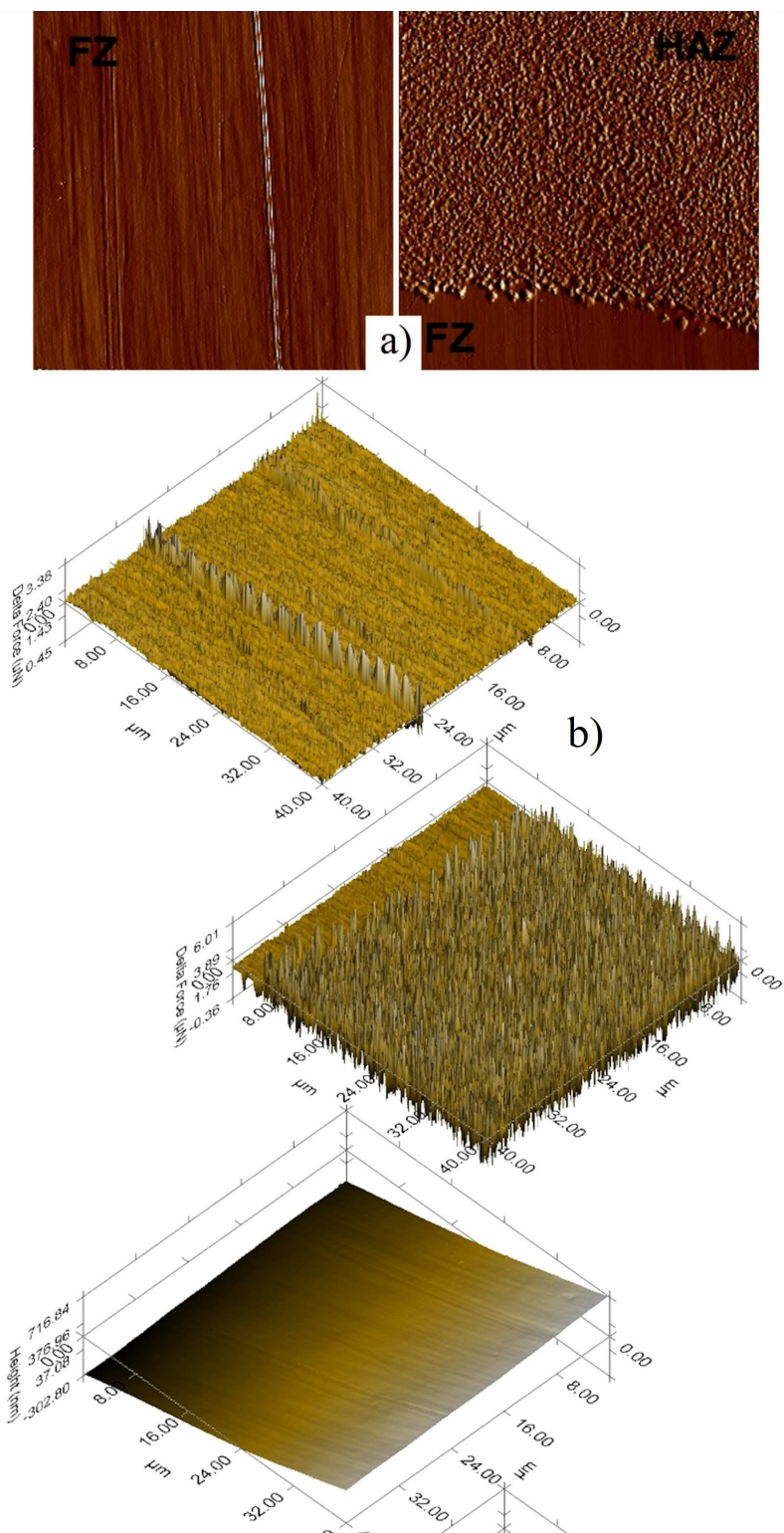

c)

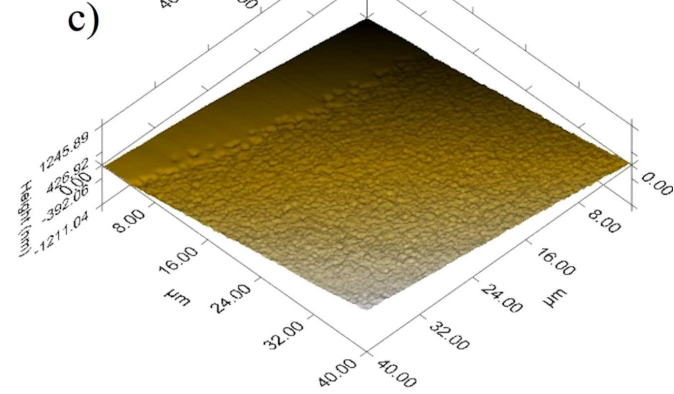

Fig. 3. The surface morphology of the $\mathrm{Zr}-\mathrm{Cu}-\mathrm{Ni}-\mathrm{Al}$ laser weld in the fusion zone and the heat affected zone: 2D gradient (a), 3D gradient (b), topography (c) forward direction (Hysitron TI 950 Triboindenter with the Berkovich indenter). 
Representative results of the cross-sectional analysis of the $\mathrm{Zr}_{55} \mathrm{Cu}_{30} \mathrm{Ni}_{5} \mathrm{Al}_{10}$ alloy weld obtained with the scanning electron microscope are shown in Fig. 2. The obtained results confirm the amorphous and crystalline structure at the boundary of the heat affected zone and the fusion zone. The melting zone is smooth, without visible etching grooves. The smooth surface of the melting zone after etching may suggest the presence of an amorphous phase.

Thanks to the experiment provided by triboindenter it is very probable that the structure in investigated sample is partially amorphous (Fig. 3). The amorphous structure in fusion zone has also been confirmed by atomic force microscopy (AFM) and high resolution transmission electron microscopy (HRTEM) analysis published in [8]. Patterns coniferous are located in the heat affected zone. There are inequalities that confirm the occurrence of the crystalline phase.

The delicate surface texture shown in Fig. 3 is the result of the direct interaction of the laser beam on the amorphous material and subsequent rapid cooling of the melted metallic liquid on the zirconium matrix. There is a surface without visible roughness in the fusion zone.

The topography of the surface in the zone between the melted area and the original material shows a thickening from the melting and distinctive roughness which reflect the presence of crystallites.

The roughness was formed along the laser pulse line, forming a clear boundary between the melted zone and the heat-affected zone (Fig. 3). Figure 3 clearly shows a boundary where the nuclei of crystallization are formed and where they grow.

Nanohardness of the parent material is $6.69 \mathrm{GPa}$, $6.94 \mathrm{GPa}$ in the melt zone and $6.08 \mathrm{GPa}$ in the heataffected zone. A slightly lower nanohardness in the HAZ may result from the heterogeneity of the material in this zone, as also indicated by the measurement results shown in Fig. 4. The slightly lower hardness in the laser cladding zone was observed in the work [9]. According to Liu [10] the nanohardness of irradiated metallic glass surface was decreased, too.

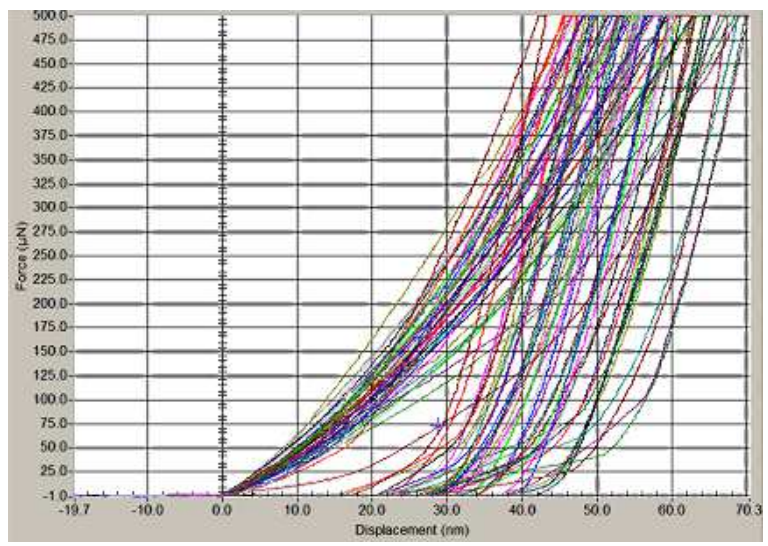

Fig. 4. The diagram of indenter displacement as a function of load for the surface of the heat-affected zone.
The value of $E_{r}$ depends on the atomic ordering in the material and the chemical composition of the alloy. The value of $E_{r}$ measured at the cross-section of the $\mathrm{Zr}_{55} \mathrm{Al}_{10} \mathrm{Ni}_{5} \mathrm{Cu}_{30}$ alloy joint is in the range of $90.10 \mathrm{GPa}$ to $91.60 \mathrm{GPa}$.

\section{Conclusions}

Due to the small weld size of $0.5-3.5 \mathrm{~mm}$ and the metastable structure of the welded material, structural testing has been carried out with an X-ray diffractometer with special optics, a scanning electron microscope and a triboindenter.

Studies have shown the amorphous-crystalline nature of the heat affected zone and have confirmed the presence of the amorphous phase in fusion zone. The detailed topographic analysis revealed that the heat affected zone demonstrated a slight roughness characteristic of the crystalline phase and a smooth surface in the fusion zone. The joint surface with non-homogeneous topography exhibits slightly lower nanohardness compared to the nanohardness of smooth fusion zone and parent material surfaces. $E_{r}$ value is restricted in the range of 105.76 GPa (parent material)-108.80 GPa (heat affected zone). $H_{v}$ value is restricted in the range of $6.08 \mathrm{GPa}$ (heat affected zone)-6.94 GPa (fusion zone). The $E_{r}$ and $H_{v}$ values are at similar levels in heat affected zone, fusion zone and parent material.

\section{Acknowledgments}

This work was partially supported by National Science Centre (NCN) (project no. 2011/01/D/ST8/07327).

\section{References}

[1] H.S. Wang, H.G. Chen, J.S.C. Jang, M.S. Chiou, Mater. Sci. Eng. A Struct. 528, 338 (2010).

[2] B. Li, Z.Y. Li, J.G. Xiong, L. Xing, D. Wang, Y. Li, J. Alloys Comp. 413, 118 (2006).

[3] J. Kim, D. Lee, S. Shin, C. Lee, Mater. Sci. Eng. A Struct. 434, 194 (2006).

[4] Y. Kawahito, T. Terajima, H. Kimura, T. Kuroda, T. Nakata, S. Katayama, A. Inoue, Mater. Sci. Eng. B 148, 105 (2008).

[5] W. Pilarczyk, A. Pilarczyk, Mater. Technol. 49, 537 (2015).

[6] T. Lipiński, Arch. Metall. Mater. 60, 321 (2015).

[7] W. Pilarczyk, Appl. Surf. Sci. 374, 359 (2016).

[8] W. Pilarczyk, Structure and Properties of Bulk Metallic Glasses in As-Cast State and after Laser Welding, monography, Publisher of the Silesian University of Technology, Gliwice 2017.

[9] Y.Y. Zhu, Z.G. Li, R.F. Li, M. Li, X.L. Daze, K. Feng, Y.X. Wu, Appl. Surf. Sci. 280, 50 (2013).

[10] X. Liu, X. Mei, J. Qiang, G.E. Remnev, Y. Wang, Appl. Surf. Sci. 313, 911 (2014). 